\title{
Selective separation of Ge(IV) from simulated industrial leachates containing heavy metals by non-dispersive ionic extraction
}

\author{
Hossein Kamran Haghighi ${ }^{\mathrm{a}}$, Mehdi Irannajad ${ }^{\mathrm{a}}$, Maria Teresa Coll ${ }^{\mathrm{b}}$, Ana Maria Sastre ${ }^{\mathrm{c}}$ \\ a Department of Mining and Metallurgical Engineering, Amirkabir University of Technology, \\ Tehran, Iran \\ b Department of Chemical Engineering, Universitat Politècnica de Catalunya, EPSEVG, Av. \\ Víctor Balaguer s/n, 08800 Vilanova i la Geltrú, Spain. \\ c Department of Chemical Engineering, Universitat Politècnica de Catalunya, ESTEIB, Av. \\ Diagonal 647, 08028 Barcelona, Spain
}




\begin{abstract}
Germanium can be found in industrial leachates of coal gasification fly ashes or zinc plant residues, containing various heavy metals. In this research, the selective separation of germanium from simulated water coal gasification fly ash leach liquors containing $\mathrm{Zn}(\mathrm{II}), \mathrm{Ni}(\mathrm{II})$, $\mathrm{Cd}(\mathrm{II})$, and $\mathrm{Co}(\mathrm{II})$ through the flat sheet and hollow fiber supported ionic liquid membrane (FSSLM \& HFSLM) systems was developed using an ionic liquid Aliquat 336 as a carrier. As a result, Aliquat-336 was a very fast and effective carrier for the selective transport from these types of solutions. The selective transport of germanium through the mentioned FSSLM system was carried out from a simulated zinc acidic leach liquor containing the aforementioned metals and $0.5 \mathrm{~mol} / \mathrm{L}$ of $\mathrm{H}_{2} \mathrm{SO}_{4}$ under the condition found for the neutral solutions. As a result, an insignificant difference was observed between the germanium transports from both solutions. The germanium transport from both types of solutions was selective and its efficiency reached $>98 \%$. Finally, a facilitated transport of germanium was conducted in an HFSLM under the same condition obtained for the FSSLM system. It was observed that this system could transport major amounts of germanium species in the first 30 min showing faster transport than the FSSLM system.
\end{abstract}

Keywords: Supported liquid membrane; Ge(IV); Aliquat 336; Selective separation; heavy metals

\title{
1. Introduction
}

Germanium compounds such as $\mathrm{GeO}_{2}$ are widely used in many industries such as optics, telecommunication, alloys etc. (Liu et al., 2015; Rieke, 2007). Germanium is a critical element found in restricted resources. Therefore, it is important to recover this rare metalloid from these restricted resources. Coal fly ashes and zinc plant residues are waste materials, the management of which can eliminate their potential risks and make economical values. The industrial effluents 
obtained from zinc and fly ash purification processes are potential resources of germanium. Germanium can be found in coal gasification fly ash water leachate and acidic solutions of zinc ore/residue leaching processes. Germanium in these effluents is found along with some heavy metals such as zinc, nickel, cobalt etc. (Arroyo et al., 2009b; Liu et al., 2016; Sethurajan et al., 2017). One of the appropriate processes for germanium extraction from coal gasification fly ashes is water leaching (Arroyo and Fernández-Pereira, 2008; Arroyo et al., 2009b). The presence of heavy metals in coal fly ashes (Chaudhary and Banerjee, 2007; Sijakova-Ivanova et al., 2011) can be unwanted metals affecting the separation of germanium. Furthermore, zinc ores or related residues obtained from zinc industries are commonly leached in the sulfuric acid medium (Liu et al., 2016; Nusen et al., 2015). The presence of heavy metals such as cadmium, nickel, cobalt, and iron is common in zinc resources (Kamran Haghighi et al., 2015; Nusen et al., 2015). Therefore, the separation of germanium from these unwanted heavy metals can be valuable. Various types of hydrometallurgical processes such as solvent extraction (Nusen et al., 2015), adsorption (Marco-Lozar et al., 2007), membrane process (Takemura et al., 2013), ion exchange (Arroyo and Fernández-Pereira, 2009), and precipitation (Liang et al., 2008) were used in the recovery of germanium from aqueous solutions. Some advantages such as high selectivity, high capacity, rapid extraction, and production of a pure product have caused the dispersive solvent extraction process to be significant in the purification industries (Wei et al., 2016). The SLM systems such as hollow fiber (HFSLM) and flat sheet (FSSLM) can be considered as nondispersive solvent extraction having some similarities to solvent extraction. The extraction and stripping mechanisms of both methods are the same, but these stages in SLM systems are simultaneously carried out in a process. Higher selectivity, low capital and operational costs, operative easiness, and low extractant consumption are the other advantages of SLM systems 
(Chaturabul et al., 2015; Kandwal et al., 2011; Yang et al., 2002). These advantages will be effective when a solution containing valuable trace metals such as germanium or rare earth elements is treated (Campderrós and Marchese, 2001). However, flat sheet SLM systems have been faced with challenges in industrial usages such as maintenance issues (Swain et al., 2015). On the other hand, a hollow fiber SLM system based on non-dispersive solvent extraction, merging solvent extraction and flat sheet SLM advantages. In this study, the effective area of HFSLM is 127000 times more than that of FSSLM. Therefore, it can be expected that the transport rate in HFSLM is comparable to solvent extraction. These advantages have spread the use of HFSLM in industrial works (Wannachod et al., 2014).

In SLM systems, the detection of a proper extractant as a carrier of the species is vital to design a proper germanium separation process. There are many extractants used to separate and recover germanium from aqueous solutions such as KELEX 100 (Bauer et al., 1983), LIX 63 (Boateng et al., 1990; de Schepper, 1976), Ionquest 801 (Boateng et al., 1990), Cyanex 301 (Harbuck et al., 1991; Kamran Haghighi et al., 2018b), and TOA (Arroyo and Fernández-Pereira, 2008; Kamran Haghighi et al., 2018c). Ionic liquids (ILs) are the other organic materials that can be used instead of classical extractants for the recovery of species. Insignificant vapor pressures, high thermal stabilities, and good affinity towards metals are some advantages of ionic liquids (Jha et al., 2014; Wei et al., 2016; Won et al., 2014). Only two ionic liquid systems have been used to transport germanium from aqueous solutions in the literature; however, in a research tricapryloyl methyl ammonium chloride (Aliquat 336S) as a hydrophobic quaternary ammonium salt with the formula of $\left[\mathrm{R}_{3} \mathrm{NCH}_{3}\right]^{+} \mathrm{Cl}^{-}$was used to separate germanium from citric acid solutions in a liquid-liquid extraction system (Vibhute and Khopkar, 1986). According to this study, 0.1 M of Aliquat 336 diluted in xylene could selectively extract germanium among various metals from 
$0.001 \mathrm{M}$ of the citric acid solution at a $\mathrm{pH}$ of 3.5. With respect to this discussion, IL Aliquat 336 has been first used as a carrier of the supported liquid membrane in the current study. In addition, Kamran Haghighi et al. (2018a) used methyl-N, N-dioctyl chloride (Aliquat 336) to extract and separate germanium from heavy metals from a solution containing nickel, cadmium, cobalt, and zinc. The high extraction efficiency of germanium has been reported for this system.

In this research, Aliquat 336 was selected as a carrier of HF-SLM and FS-SLM systems for the selective transport of germanium from simulated solutions with similar composition to zinc resources/fly ashes leach liquors. The effects of various parameters such as Aliquat 336 concentration, complaxant concentration, and strip solution concentration were examined in details. SLM processes proposed in the present research can be considered as a novel opportunity to recover germanium from various industrial leach liquor as potential resources of germanium.

\section{Theory}

Aliquat 336 is an ionic liquid stated as $\mathrm{R}_{4} \mathrm{~N}^{+} \mathrm{Cl}^{-}$that can extract anionic species. It is a quaternary ammonium salt formed of a large organic cation along with a chloride ion. The positive ammonium part of Aliquat 336 can react with various anions in a broad pH range (Nayl, 2010). Since germanium species in water/sulfuric acid media is not in anionic form, thus, in order to form germanium anionic complexes, a complexant namely tartaric acid was used to form germanium-tartrate anionic species. In the presence of $\mathrm{C}_{4} \mathrm{H}_{6} \mathrm{O}_{6}$ in the feed solution, neutral germanium species $\left(\mathrm{H}_{2} \mathrm{GeO}_{3}\right)$ transform to $\mathrm{Ge}\left(\mathrm{C}_{4} \mathrm{H}_{4} \mathrm{O}_{6}\right)_{\mathrm{i}}{ }^{2-}$. Considering the values of the tartaric acid dissociation constants i.e. $\mathrm{pK}_{1}=3.04$ and $\mathrm{pK}_{2}=4.37$, the stability of a germanium-tartrate complex is highly dependent on the $\mathrm{pH}$. According to the literature, Ge-tartrates are not stable complexes at pHs> 7 due to the reason introduced in a study carried out by Vartapetian (1957) 
and confirmed by Pokrovski and Schott (1998). Furthermore, Ge-tartrates are decomposed at $\mathrm{pHs}<1.24$ to germanium species and free tartrate (Everest and Harrison, 1960).

Hence, Aliquat 336 can form a complex $\left(\left(\mathrm{R}_{4} \mathrm{~N}^{+}\right)_{2} \mathrm{Ge}\left(\mathrm{C}_{4} \mathrm{H}_{4} \mathrm{O}_{6}\right)_{\mathrm{i}}{ }^{2-}\right)$ with anionic species of germanium at the feed phase-membrane diffusion layer. This complex diffuses across the membrane phase and is stripped with a stripping reagent $(\mathrm{HCl})$ in the receiving phase-membrane diffusion layer. Fig. 1 illustrates the schematic germanium transport through the ionic liquid membrane of this study.

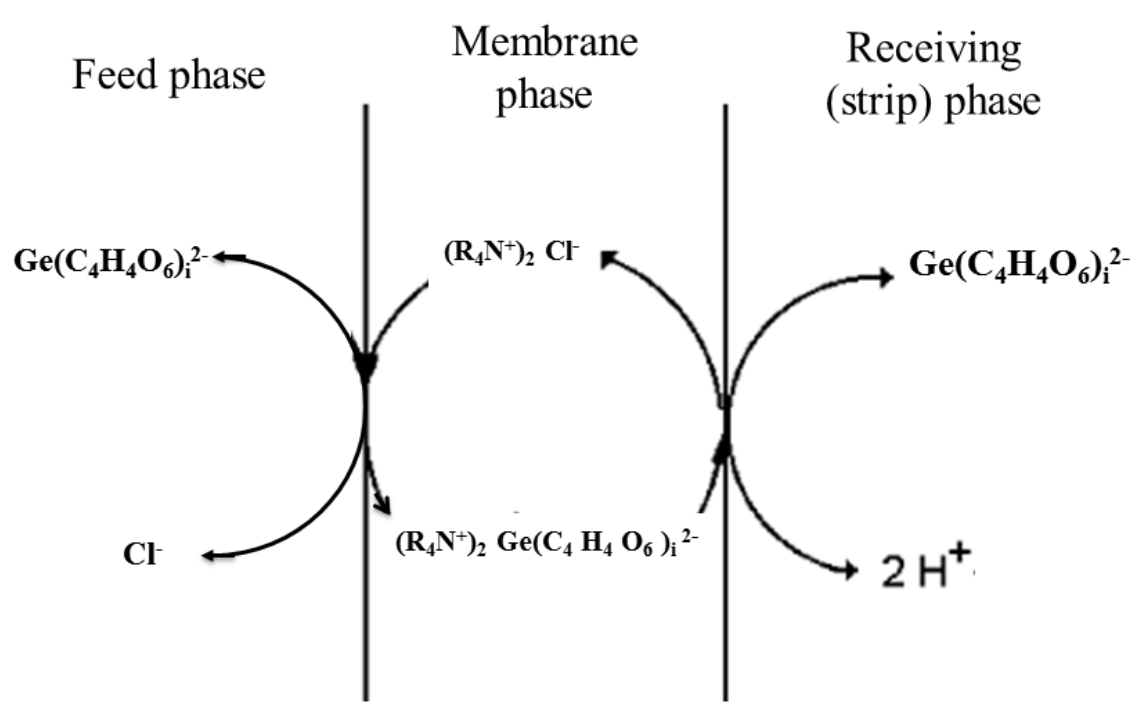

Fig. 1. The schematic transport of germanium through the ionic liquid membrane The usual parameter to control the system is permeability coefficient $\mathrm{P}(\mathrm{cm} / \mathrm{s})$. It can be calculated using the slope of the plot of $-\frac{V}{A} \ln \left(C_{f} / C_{f_{t}}\right)$ vs. time with respect to Eq. (1):

$\ln \left(C_{f} / C_{f . t}\right)=-\frac{A P t}{V}$

Where $\mathrm{V}$ represents the volume of feed phase and A shows the effective area of the membrane. 


\section{Materials and methods}

\subsection{Materials}

Coal gasification fly ashes contained many heavy metals and trace elements. However, their water leachates may contain germanium, arsenic, iron, arsenic, nickel, antimony, vanadium, and the other heavy metals. On the other hand, nickel, iron, cadmium, cobalt, zinc as well as germanium are the main elements in acidic leachates of Iranian zinc residues. According to the literature, divalent metal ions such as manganese, magnesium, calcium, strontium are not reacted with citric and tartaric acids, meaning that they can not be extracted by amine extractants such as Aliquat 336 (Vibhute and Khopkar, 1986). Furthermore, other elements such as arsenic, antimony, vanadium etc. which may exist in the coal gasification fly ash leachates can not be stripped by an acid (Arroyo et al., 2009a). Hence, since this study deals with two types of leachates (from zinc residues and gasification fly ashes) containing germanium and according to the aforementioned discussion, to ease the comparison and the interpretation of systems, only zinc, cadmium, cobalt, and nickel as well as germanium were selected for the investigation. It is noteworthy that all solutions had the initial pHs around 4, in which ferric iron was precipitated. Therefore, it is supposed that all solutions are iron-removed leachates. In order to simulate the water leach liquor of coal gasification fly ash, synthetic solutions containing $1000 \mathrm{mg} / \mathrm{L}$ of $\mathrm{Zn}$, $100 \mathrm{mg} / \mathrm{L}$ of $\mathrm{Ge}, \mathrm{Cd}, \mathrm{Co}$, and $\mathrm{Ni}$ were prepared by dissolving the desired amounts of $\mathrm{ZnSO}_{4} \cdot 7 \mathrm{H}_{2} \mathrm{O}, \mathrm{GeO}_{2}, \mathrm{CdSO}_{4}, \mathrm{CoSO}_{4} \cdot \mathrm{H}_{2} \mathrm{O}$, and $\mathrm{NiSO}_{4} \cdot 6 \mathrm{H}_{2} \mathrm{O}$ (Aldrich A.C.S. Reagent) in pure distilled water. Aliquat $336\left(\mathrm{R}_{4} \mathrm{~N}-\mathrm{Cl}\right)$ from Alfa Aesar, Germany diluted in desired volumes of 
kerosene (Aldrich A.C.S. Reagent) and 1-Decanol (Merck Millipore, Germany) formed the carrier of the SLM systems. Purified water used in this study was supplied using water purifiers (Siemens, Germany) during the experiments. The other materials used in this research were purchased from Merck, Germany. After finding the effect of various parameters, an FSSLM experiment was carried out to evaluate the effect of sulfuric acid on the transport of germanium. The aim of this experiment was to obtain a process for the separation of germanium from solutions obtained from sulfuric acid leaching of zinc ores. In this regard, a solution with a sulfuric acid concentration of $0.5 \mathrm{~mol} / \mathrm{L}$ was prepared. The desired amounts of $\mathrm{ZnSO}_{4} \cdot 7 \mathrm{H}_{2} \mathrm{O}$, $\mathrm{GeO}_{2}, \mathrm{CdSO}_{4}, \mathrm{CoSO}_{4} \cdot \mathrm{H}_{2} \mathrm{O}$, and $\mathrm{NiSO}_{4} \cdot 6 \mathrm{H}_{2} \mathrm{O}$ were added to this solution to obtain a solution with the concentrations of 15000, 100, 100, 100, and 100 for $\mathrm{Zn}(\mathrm{II}), \mathrm{Ge}(\mathrm{IV}), \mathrm{Cd}(\mathrm{II}), \mathrm{Co}(\mathrm{II})$, and $\mathrm{Ni}(\mathrm{II})$, respectively. Similar to the zinc leaching industries, an amount of neutralizer such as $\mathrm{NaOH}$ was added to neutralize the solution until a pH of 3.5 was achieved.

\subsection{Flat sheet supported liquid membrane}

The flat sheet supported liquid membrane experiments were run in two cells with an effective membrane area of $11 \mathrm{~cm}^{2}$ to separate germanium from heavy metals similar to a schematic diagram shown in Fig. 2. The cell of the feed phase $(220 \mathrm{~mL})$ was detached from the strip phase cell $(220 \mathrm{ml})$ by a liquid membrane placed in a flanged chamber. As mentioned before, the carrier phase of the membrane contained Aliquat 336 diluted in kerosene and 1-decanol. Polyvinylidene fluoride (PVDF) and polytetrafluorethylene (PTFE) are common commercial membranes having good physical and chemical resistance (Iorhemen et al., 2016; Le and Nunes, 2016). They have appropriate abilities in the facilitated transport systems, in which various species can be permeated (Bhatluri et al., 2014; Panja et al., 2008; Swain et al., 2007; Swain et al., 2006). Thus, polymeric Durapore ${ }^{\circledR}$ disc membranes, FHLP series of PTFE film with a 
porosity of $85 \%, 47 \mathrm{~mm}$ diameter, and pore size of $0.45 \mu \mathrm{m}$ and Millipore HVHP04700 Durapore PVDF membrane with hydrophobic nature, pore size of $0.45 \mu \mathrm{m}$, diameter of $47 \mathrm{~mm}$, and thickness of $125 \mu \mathrm{m}$, were used as the polymeric supports. The membranes were impregnated in various concentrations of diluted Aliquat 336 for few minutes followed by rinsing distilled water to eliminate additional organic extractants from the surface of the membrane film and placing it in the plunged chamber between two cells. This membrane plays the role of hydrophobic separator between feed and strip phases. The extractant in the pores of the membrane acts as a mobile carrier for extraction purposes. Hydrochloric acid solutions were used as the stripping phase. Moreover, the feed and strip phases in the two cells were agitated using a mechanical stirrer at room temperature $\left(22 \pm 1^{\circ} \mathrm{C}\right)$. At desired times, $0.5 \mathrm{~mL}$ volumes of samples were taken from both sides and the concentrations of ions were analyzed by inductively coupled plasma atomic emission spectroscopy (ICP-AES Agilent, USA).

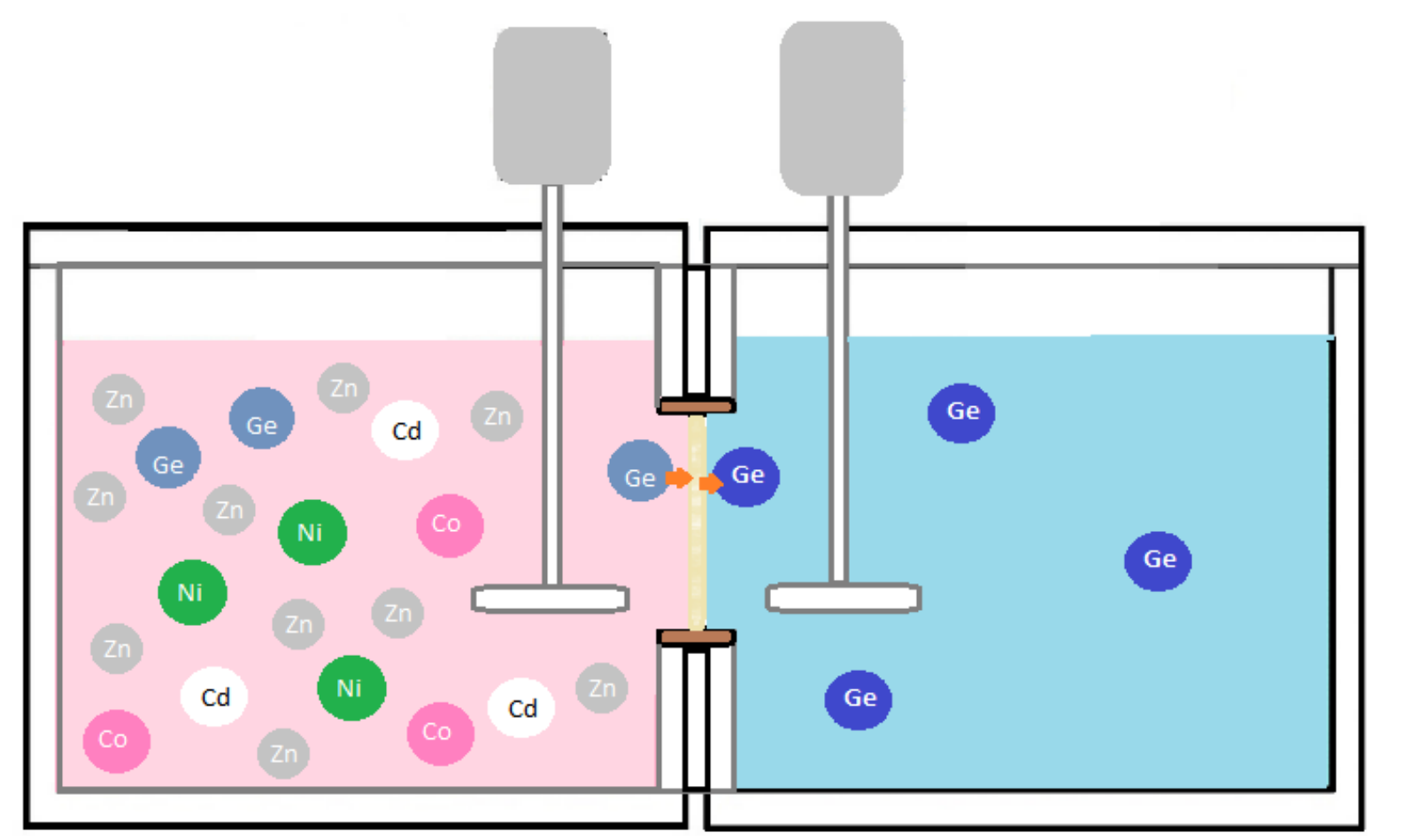




\subsection{Hollow fiber supported liquid membrane (HFSLM)}

A hollow fiber supported liquid membrane (HFSLM) system was used in this experiment as illustrated in Fig. 3. In this system, a hollow fiber module was placed as a contacor of strip and feed phases. This module had an operational membrane area of $1.4 \mathrm{~m}^{2}$. Hence, it was expected that the transport rate and efficiency would be faster with this high area in comparison with the flat sheet membranes. The other characterization of the polypropylene/polyethylene Liqui-Cel, USA module was as follows: the length of $28 \mathrm{~cm}$, the diameter of $8 \mathrm{~cm}$, and the porosity of 0.40 . Before starting the experiment, the module should be saturated with Aliquat $336(5 \% \mathrm{v} / \mathrm{v})$ diluted in kerosene and 1-decanol as the carrier. In this regard, the carrier was recycled through a lumen inside the module. For complete impregnation of the pores, a quantity of pressure was applied to transport the carrier to the lumen side of the module and the operation continued until the entire organic carrier was transported to the feed container. As seen in Fig. 3, the system contained the feed and strip containers. Both of the containers were agitated with impellers. In the feed side, 2 $\mathrm{L}$ of the germanium solution with a concentration of $100 \mathrm{mg} / \mathrm{L}$ was added to the container. In addition, in the strip side, $50 \mathrm{~mL}$ of the carrier was agitated to disperse in the $500 \mathrm{~mL}$ of the $\mathrm{HCl}$ strip solution. This pseudo emulsion was recirculated from the strip phase to the lumen side of the membrane module, making a constant supply of the carrier into the membrane pores (Rathore et al., 2009). In order to monitor the system, in appropriate time intervals, $1 \mathrm{~mL}$ of a sample from the feed side and $10 \mathrm{~mL}$ from the strip side were taken. Since samples from the strip container contained organic phase, they were transferred to the separatory funnels to separate aqueous and 
organic phases. The feed solution and strip phase were simultaneously recycled by two gear pumps purchased from Micropump®, GJ Series, the US inside the shell and lumen sides.

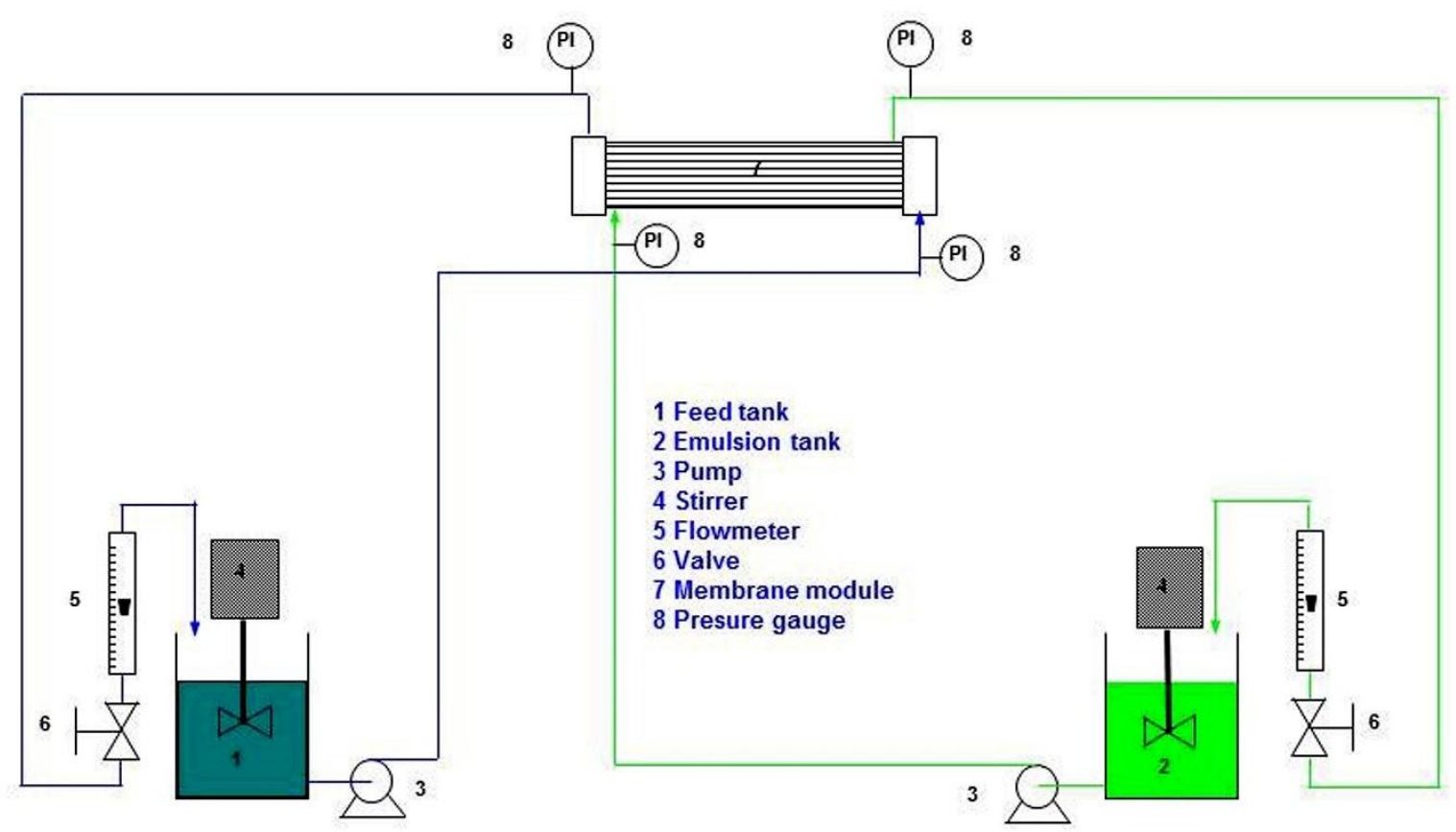

Fig. 3. A hollow fiber supported liquid membrane (HFSLM) system used in this study.

\section{Results and discussion}

\subsection{Determination of proper membrane type}

In order to detect the proper membrane for the efficient transport of germanium, two types of membranes, polyvinylidene difluoride (PVDF) hydrophobic membrane and poly tetra fluoro ethylene membrane (PTFE) were used as the supports of Aliquat 336. In this regard, PVDF and PTFE membranes with the pore size of $0.45 \mu \mathrm{m}$ were applied in the module of the FSSLM system. The experiments were run using a solution containing about $100 \mathrm{mg} / \mathrm{L}$ of $\mathrm{Ge}, \mathrm{Ni}, \mathrm{Cd}, \mathrm{Co}$ and $1000 \mathrm{mg} / \mathrm{L}$ of $\mathrm{Zn}$. The other conditions were as follows: the amount of tartaric acid equal to two times the germanium molar concentration in the feed solution $(2.76 \mathrm{mmol} / \mathrm{L})$, and the stripping $\mathrm{HCl}$ concentration of $1 \mathrm{M}$. The obtained results were plotted as Fig. 4. 


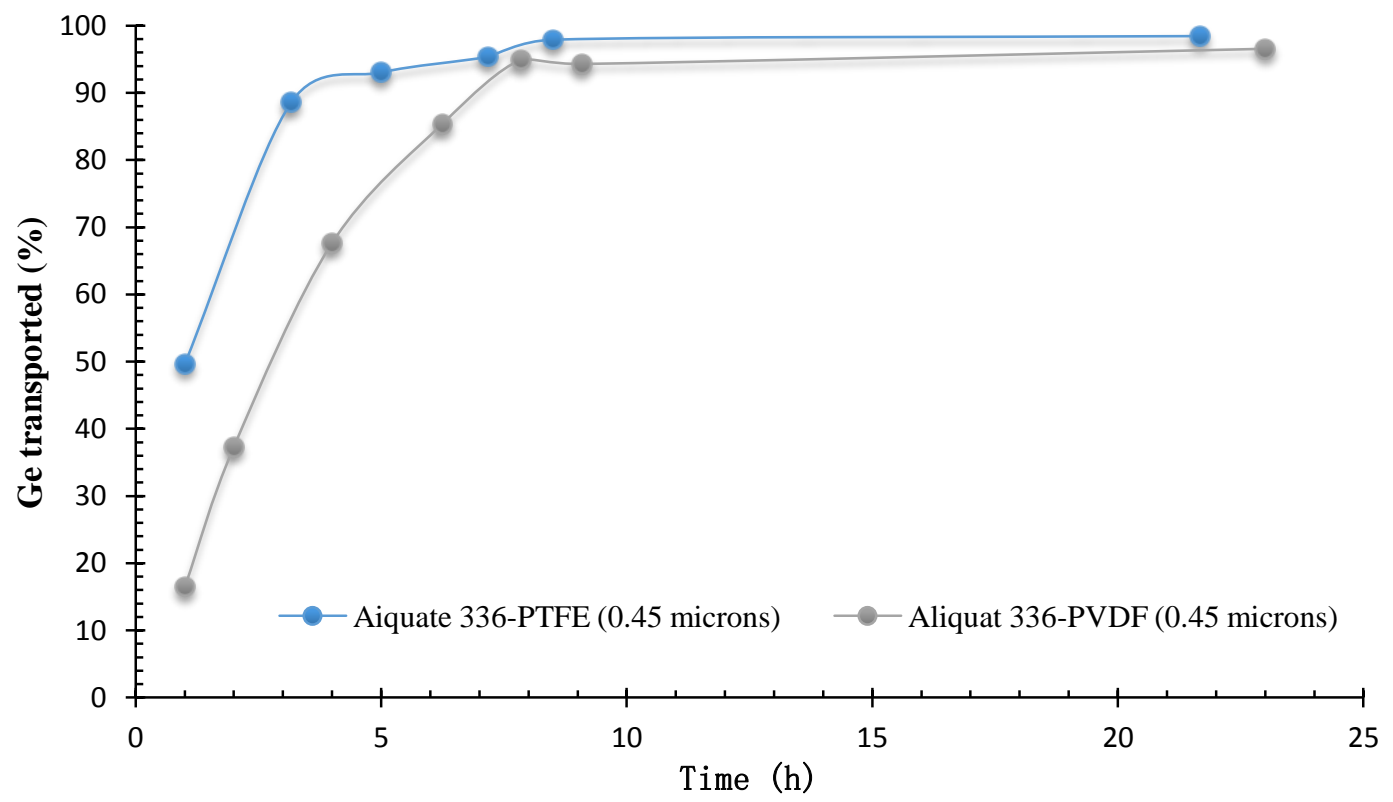

Fig. 4. Transport percentage of germanium vs. time through PTFE and PVDF membranes (100 $\mathrm{mg} / \mathrm{L}$ of $\mathrm{Ge}, \mathrm{Ni}, \mathrm{Cd}, \mathrm{Co}$ and $1000 \mathrm{mg} / \mathrm{L}$ of $\mathrm{Zn}$, the tartaric acid to Ge mole mass ratio of 2, and stripping $\mathrm{HCl}$ concentration of $1 \mathrm{M}$ ).

According to this figure, the transport percentage corresponding to the PTFE disc membrane at systems with a similar condition is higher than that of the PVDF disc membrane. It is noteworthy that the transport percentage of the other ions is close to zero and the corresponding results have not been shown. The permeability coefficients of germanium transport through the PVDF and PTFE membranes were found to be $1.98 \times 10^{-3}$ and $2.65 \times 10^{-3} \mathrm{~cm} / \mathrm{s}$, respectively. Hence, the PTFE membrane type was a proper membrane for the facilitated transport of germanium by Aliquat 336 carrier. Such results were reported in the literature. PFTE membranes have improved efficiency in operations and greater mass transfer coefficient (Adnan et al., 2012; Zhang et al., 2009). 


\subsection{Effect of carrier concentration}

The effect of the carrier concentration on the selective transport of germanium from a solution containing $100 \mathrm{mg} / \mathrm{L}$ of $\mathrm{Co}(\mathrm{II}), \mathrm{Cd}(\mathrm{II}), \mathrm{Ni}(\mathrm{II})$, and $1000 \mathrm{mg} / \mathrm{L}$ of $\mathrm{Zn}(\mathrm{II})$ was investigated in the concentration range of $0.5-10 \% \mathrm{v} / \mathrm{v}$ in an FSSLM system with a PTFE disc membrane with the pore size of $0.45 \mu \mathrm{m}$. The initial $\mathrm{pH}$ of the feed solution (after the addition of tartaric acid to the water medium) was $2.63 \pm 0.10$. According to the discussion carried out in the theory section, the Aliquat 336 molecules within the membrane phase form complexes with germanium anionic species in the diffusion layer and carry the germanium through the membrane toward the receiving side. Therefore, this transport is facilitated and accelerated by increasing the carrier concentration. However, the presence of more carrier concentration in the FSSLM system has an inverse effect on the transport. The extra concentration of the carrier enhances the viscosity of the solvent in the liquid membrane and decelerates the transport rate of germanium species across the membrane.(Bhatluri et al., 2014) The dynamic viscosity increases from 1.46 to 2.77 cP by enhancing the Aliquat 336 concentration from 0.5 to $10 \% \mathrm{v} / \mathrm{v}$. Therefore, the determination of an optimum concentration of the carrier to concise the mentioned advantages and disadvantages is vital in an FSSLM system.

Fig. 5 shows the germanium transport efficiency across FSSLM using various concentrations of Aliquat 336. As seen in this figure, the transport percentage of germanium for Aliquat 336 concentration of 0.5 and $1 \% \mathrm{v} / \mathrm{v}$ was less than $10 \%$ after prolonging time up to $21 \mathrm{~h}$. This fact showed that these concentrations were not enough for forming complexes of germanium anionic 
species and carrier molecules. However, the transport efficiencies were significantly enhanced by increasing the carrier concentration.
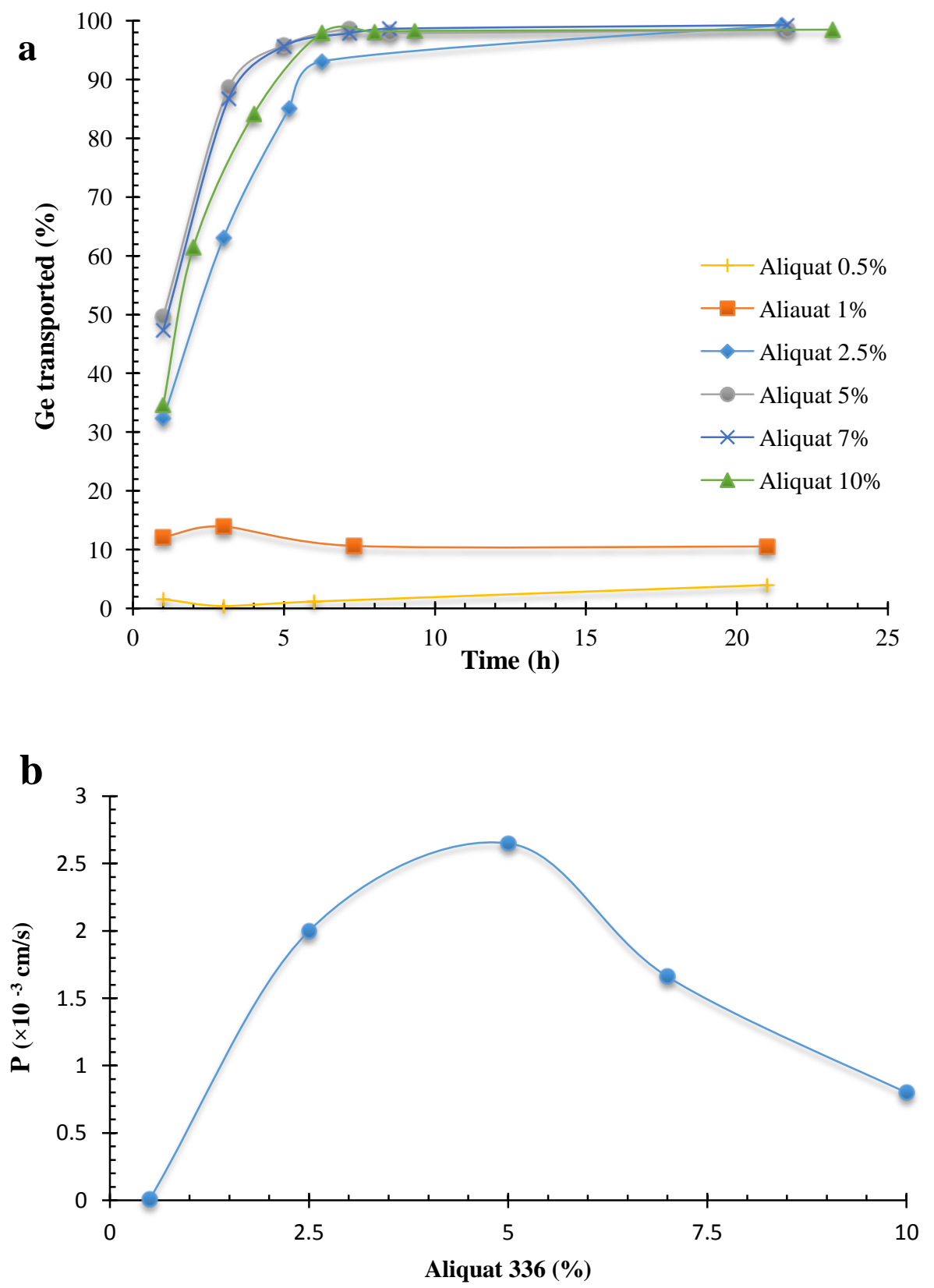

Fig. 5. (a) The transport efficiency of germanium vs. time through PTFE using various concentrations of Aliquat 336 and (b) the effect of carrier concentration on the permeability 
coefficient of germanium $(100 \mathrm{mg} / \mathrm{L}$ of Ge, Ni, Cd, Co and $1000 \mathrm{mg} / \mathrm{L}$ of $\mathrm{Zn}$, the tartaric acid to Ge mole mass ratio of 2, and stripping $\mathrm{HCl}$ concentration of $1 \mathrm{M}$ ).

As seen in Fig. 5(a), there is not a significant difference among the transport curves for the carrier concentrations in the range of 5-10\%. In this range, after $20 \mathrm{~h}$, all the germanium was approximately transported to the receiving phase. Furthermore, Fig. 5(b) illustrates the permeability coefficient variations versus Aliquat 336 concentration. With respect to this figure, the permeability reached the maximum value of $2.65 \times 10^{-3} \mathrm{~cm} / \mathrm{s}$ at the carrier concentration of $5 \%$. After this point, the permeability coefficient reduced. This reduction may occur due to an increase in the viscosity of the carrier at the interface of the liquid membrane resulting in the reduction of the species diffusion rate.(Bhatluri et al., 2014; Chakrabarty et al., 2009) Taking into account the inverse relation of the permeability and the viscosity in high viscosity liquids, this reduction can be justified (Hiss and Cussler, 1973).

In order to find the selectivity of the germanium transport among heavy metals existing in the solution, the selectivity factor was used for calculation as in Eq. (2):

$\alpha_{G e l M e}=\frac{P_{G e}}{P_{M e}}$

Where $\mathrm{P}$ denotes the permeability coefficient and Me depicts the metal. The calculated results were listed in Table 1. As seen in this table, since the transport of germanium in the carrier concentration below $2.5 \% \mathrm{v} / \mathrm{v}$ is lower than $10 \%$, the selectivity factors for these concentrations could not be calculated. The values of separation factors showed that germanium was readily separated from $\mathrm{Cd}(\mathrm{II})$ and $\mathrm{Co}(\mathrm{II})$ at any concentration. Furthermore, the complete separation of germanium from $\mathrm{Zn}(\mathrm{II})$ was done at the concentration of 2.5 and $5 \% \mathrm{v} / \mathrm{v}$; however, at higher concentrations of 7 and $10 \% \mathrm{v} / \mathrm{v}$, the separation was not completely carried out. In addition, a 
good separation between zinc and nickel was observed. Despite the incomplete separation in some concentrations, the transport efficiencies for heavy metals were less than $0.5 \%$ indicating their negligible transport.

Table 1. Selectivity factor in various concentrations of Aliquat 336 (in the same condition mentioned in Fig. 5).

\subsection{Effect of tartaric acid $\left(\mathrm{C}_{4} \mathrm{H}_{6} \mathrm{O}_{6}\right)$ addition}

As mentioned before, the presence of a complexant in a solution containing germanium is important to convert it to anionic species. Catechol as an organic reagent and carboxylates such as citric acid and tartaric acid are some materials that can be used for this conversion. According to the liquid-liquid extraction experiments, the results of which are published elsewhere, tartaric acid is an efficient and environmental-friendly material that could be used in the current study. In this regard, this complexant was selected for use in this study. In order to find the effect of the tartaric acid amount in the feed solution on the formation of anionic germanium species and its transport, a series of experiments were conducted by changing the mol mass ratio of tartaric acid to $\mathrm{Ge}(\mathrm{IV})$ of the feed phase in the range of $0-2$. Since the germanium concentration in the initial 
feed solution is $100 \mathrm{mg} / \mathrm{L}(1.38 \mathrm{~mol} / \mathrm{L})$; thus, the amount of tartaric acid added to the solution is a multiple of $1.38 \mathrm{mmol} / \mathrm{L}$. The results were illustrated in Fig. 6. As seen in this figure, with prolonging time up to the equilibrium condition, the transport efficiencies were enhanced. Moreover, the results showed that by increasing the tartaric acid amount to the feed phase, the transport efficiency increased. However, after an amount of 1.5 (of tartaric acid to Ge molar ratio), the efficiency was not significantly changed. As a result, the complete transport of germanium (100\%) from the feed solution to the receiving solution was done at the tartaric acid to Ge ratio of 2. Table 2 shows the permeability coefficient of germanium transport through the FSSLM system. Since the transport in the lower tartaric acid concentrations is not complete, the permeability coefficient could not be calculated. As seen in this table, the permeability coefficient rises with an increase of tartaric acid. However, the increase rate at the concentration equal to 2 times of tartaric acid decreases.

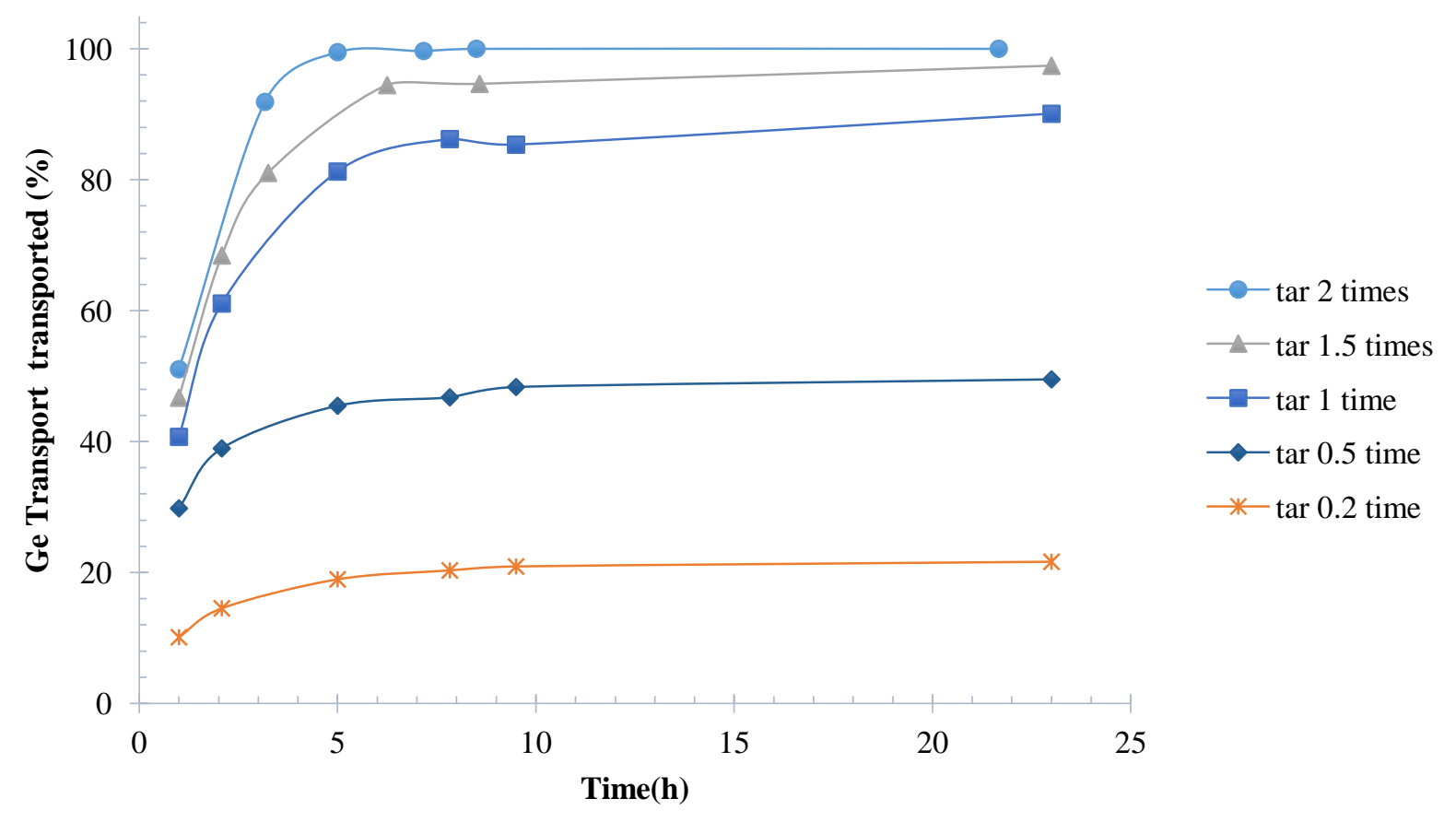


Fig. 6. Effect of tartaric acid on the germanium transport (Ge, Ni, Cd, and Co of $100 \mathrm{mg} / \mathrm{L}$ as well as $\mathrm{Zn} 1000 \mathrm{mg} / \mathrm{L}$, Aliquat 336 concentration of $5 \% \mathrm{v} / \mathrm{v}$ and $\mathrm{HCl}$ concentration of $1 \mathrm{M}$ ).

Fig. 7 shows the transport efficiency of heavy metals transported through the membrane. As seen in this figure, the transport efficiency of zinc decreased with an enhancement of the tartaric acid up to $0 \%$ at the 2 molar ratios. Also, the transport of nickel was increased up to a steady level of $1 \%$ after the addition of 1 mol mass ratio of tartaric to Ge. Moreover, the values of cadmium transport efficiency did not show a specific trend. Since the transport efficiency of these metals is less in comparison to germanium transport, these unordinary variations are not significant.

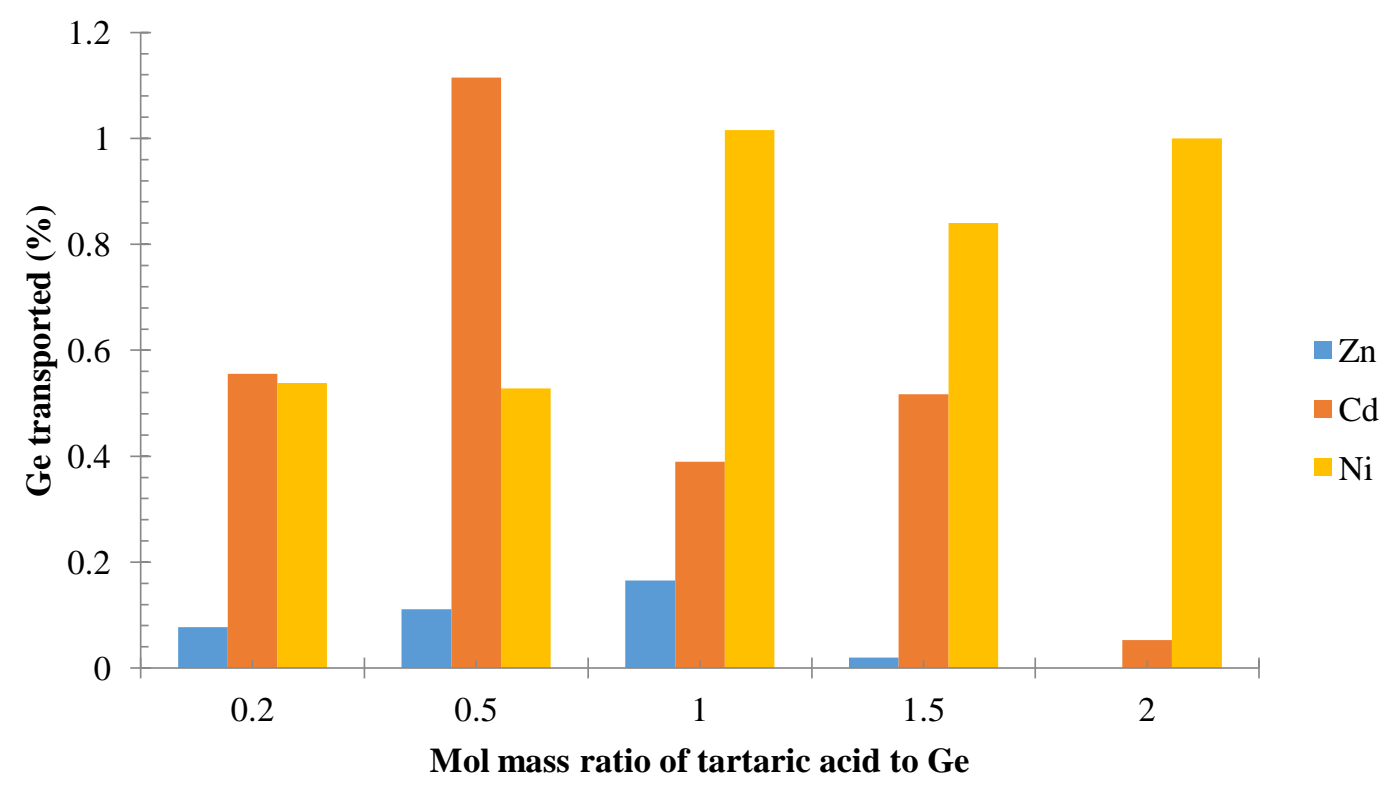

Fig. 7. Effect of tartaric acid on the transport of heavy metals (with the same condition mentioned in Fig. 6). 
Table 2. Effect of the tartaric acid amount on the permeation coefficient (the condition is as mentioned in Fig. 6)

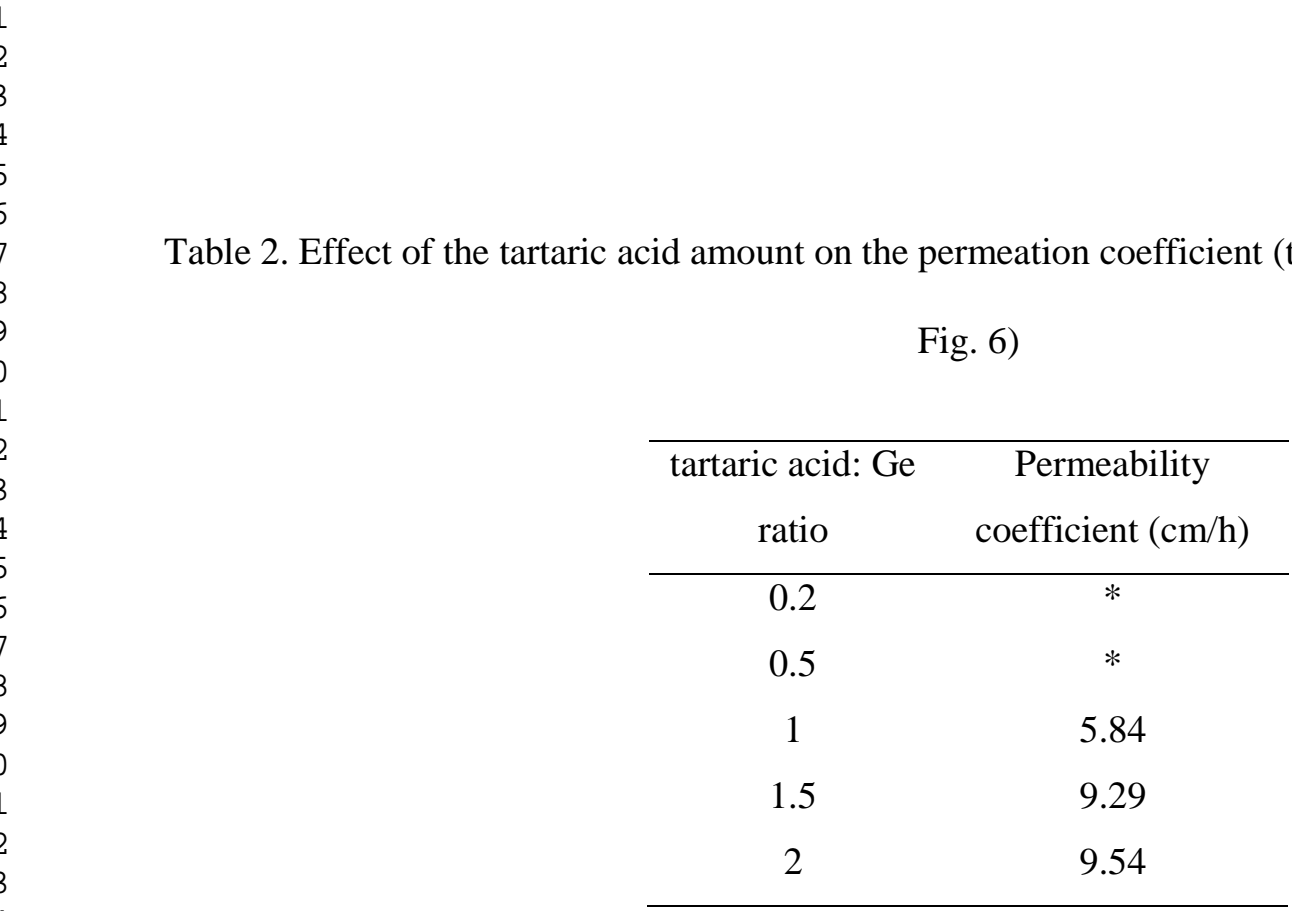

\subsection{Effect of $\mathrm{HCl}$ concentration as the receiving solution on the permeation}

According to the liquid-liquid extraction studies, hydrochloric acid is an efficient acidic reagent for the stripping of extracted germanium. The stripping efficiency of various concentrations of $\mathrm{HCl}$ in the receiving solution was investigated in the range $0.25-2.0 \mathrm{M}$. Fig. 8 illustrates the effect of $\mathrm{HCl}$ on the transport efficiency of germanium. The figure obviously shows the enhancement of the transport efficiency with an increase in $\mathrm{HCl}$ concentration. The preliminary growth in the germanium transport corresponding to the $\mathrm{HCl}$ concentrations less than $1 \mathrm{M}$ is because of the increase in the germanium species decomplexation occurred at the interface. The transport efficiency for the $\mathrm{HCl}$ concentrations of $0.5-2 \mathrm{M}$ approximately remained constant; however, for the concentration of $1 \mathrm{M}$, it tended to be maximum. In the strip solution concentration above $1 \mathrm{M} \mathrm{HCl}$, the extracted germanium species by the carrier are decomposed and this process is induced by the interfacial reactions during the stripping. At the mentioned concentrations, this decomposition takes place rapidly, as the following diffusion of species into the strip solution does not depend on the acid concentration. Consequently, the proton 
concentration gradient in the stripping phase does not create an important driving force during the transport of germanium.(Duan et al., 2017) According to the literature, this behavior occurs because the driving force saturation for the diffusion across the membrane takes place when metal compound concentrations enhance at the interfacial level in the membrane-strip solution interface.(Venkateswaran and Palanivelu, 2005) Moreover, the effect of $\mathrm{HCl}$ on the transport of heavy metals in the feed solution showed that the transport of these metals is not significant in comparison to germanium transport because the transport efficiencies of all these metals were less than $0.5 \%$.

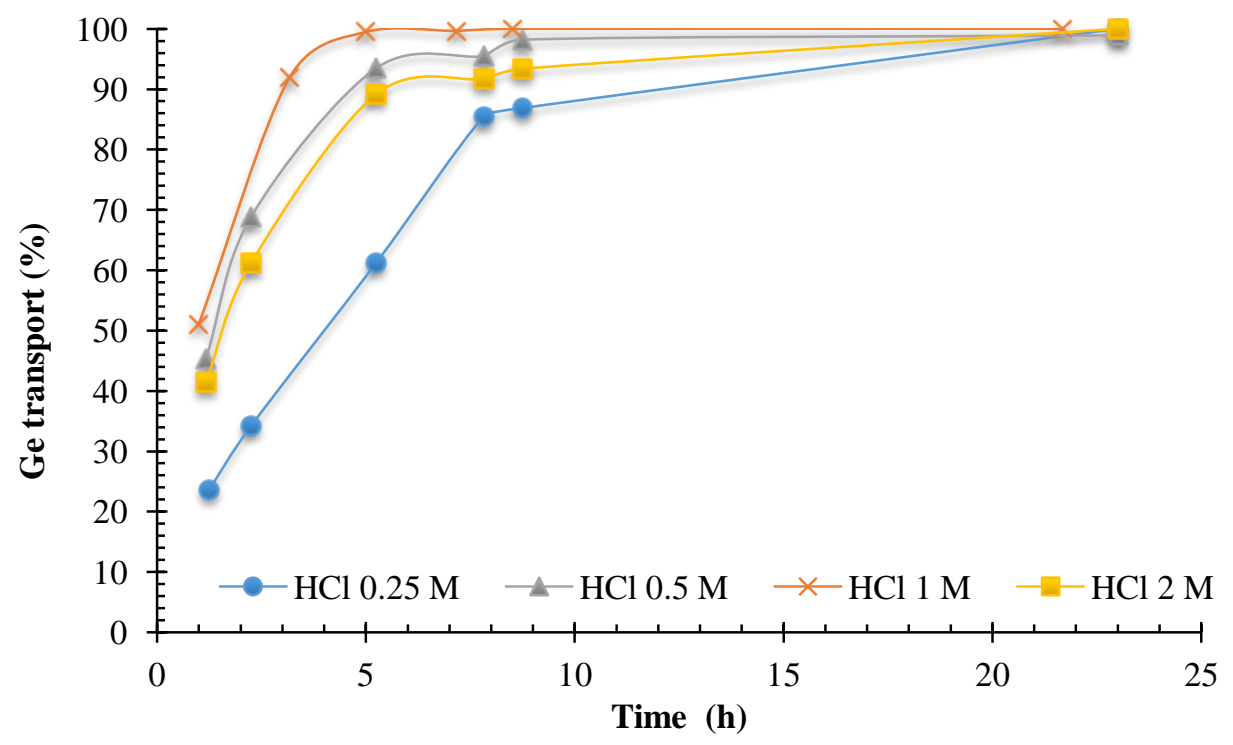

Fig. 8. Effect of hydrochloric acid in the strip phase on the transport of germanium $(\mathrm{Ge}, \mathrm{Ni}, \mathrm{Cd}$, and Co of $100 \mathrm{mg} / \mathrm{L}$ as well as $\mathrm{Zn} 1000 \mathrm{mg} / \mathrm{L}$, Aliquat 336 concentration of $5 \% \mathrm{v} / \mathrm{v}$, the tartaric acid to $\mathrm{Ge}$ mole mass ratio of 2 , and $\mathrm{HCl}$ concentration of $1 \mathrm{M}$ ).

\subsection{Transport of germanium from simulated zinc leach liquor}

All the experiments in the previous sections were carried out in the water medium being the simulated solution obtained from leaching of gasification fly ashes. As discussed in the 

behavior of germanium transport through the FSSLM system of this study, an experiment was conducted in a solution containing $0.5 \mathrm{~mol} / \mathrm{L} \mathrm{H}_{2} \mathrm{SO}_{4}$ neutralized with $\mathrm{NaOH}$ solution until the $\mathrm{pH}$ reached a value of 3.5. The appropriate concentrations of $\mathrm{H}_{2} \mathrm{SO}_{4}$ for leaching of zinc ores/residues were reported to be in the range of 0.15-2 M.(Fattahi et al., 2016; Kamran Haghighi et al., 2015; Sadeghi et al., 2017; Sethurajan et al., 2017) In a sulfuric acid medium, iron commences precipitating at the $\mathrm{pH}$ of .(Claassen et al., 2002; Ismael and Carvalho, 2003; Kamran Haghighi et al., 2013) Thus, the $\mathrm{pH}$ range of the simulated solution in this study is similar to a solution in which iron has been removed by a precipitation process. An amount of tartaric acid $(2.76 \mathrm{mmol} / \mathrm{L})$ was added to this solution to keep converting germanium to anionic species. The concentrations of germanium, cadmium, nickel, and cobalt added to the aforementioned solution were about $100 \mathrm{mg} / \mathrm{L}$, whereas the concentration of zinc added was set at $15 \mathrm{~g} / \mathrm{L}$ similar to the concentration of a real zinc leach liquor. The other conditions of this system were similar to the optimum condition obtained before. Fig. 9 shows the concentrations of germanium in the feed and strip phases vs. time corresponding to the water medium (without $\mathrm{H}_{2} \mathrm{SO}_{4}$ ) and the simulated acid sulfuric zinc leach liquor. As seen in this figure, the curves corresponding to $\mathrm{H}_{2} \mathrm{SO}_{4} 1 \mathrm{M}$ and $0.5 \mathrm{M}$ show that an enhancement of the sulfuric acid concentrations in the solution changes the extraction equilibrium constant of the reaction between germanium-tartrate species with extractant molecules resulting in a reduction of transport rate at earlier times. The permeability coefficients corresponding to $1 \mathrm{M} \mathrm{H}_{2} \mathrm{SO}_{4}, 0.5 \mathrm{M}$ $\mathrm{H}_{2} \mathrm{SO}_{4}$, and water were calculated to be $1.58,2$, and $2.65\left(\times 10^{-3} \mathrm{~cm} / \mathrm{s}\right)$, respectively. Hence, the transport rate and the permeability decreased with increasing sulfuric acid concentration. imilar results have been observed in the other studies.(Bhowal and Datta, 2001; Strzelbicki et al., 1984; 

Venkateswaran and Palanivelu, 2005) The conversion of germanium-tartrate anionic species to other forms such as $\mathrm{H}_{2} \mathrm{GeO}_{3}$ or $\mathrm{Ge}^{4+}$ in higher sulfuric acid concentration can be the probable reason of the mentioned decline. Similarly, it was seen that the conversion of $\mathrm{Cr}_{2} \mathrm{O}_{7}{ }^{2-}$ species, i.e. those which could be extracted by Aliquat 336, to $\mathrm{H}_{2} \mathrm{Cr}_{2} \mathrm{O}_{7}$ and $\mathrm{HCr}_{2} \mathrm{O}_{7}^{-}$in higher acidic concentration decreased the $\mathrm{Cr}(\mathrm{VI})$ permeation through liquid membranes using Aliquat 336.(Strzelbicki et al., 1984) It is noteworthy that since the transport of the other metals was approximately close to zero, the related results were not shown. Therefore, it can be concluded that this system can efficiently separate germanium from a zinc concentrated solution in the presence of some important impurities such as cobalt, nickel, and cadmium. The remaining zinc in the feed solution can be proceeded to a zinc solvent extraction using $30 \% \mathrm{v} / \mathrm{v}$ D2EHPA for the selective separation of zinc from nickel, cadmium, and cobalt to obtain a concentrated solution containing about $90 \mathrm{~g} / \mathrm{L}$ of $\mathrm{Zn}$. This solution can be treated in an electrowinning process to obtain zinc cathodes. These results can be used to develop and design processes for the separation of germanium from zinc leach liquors.

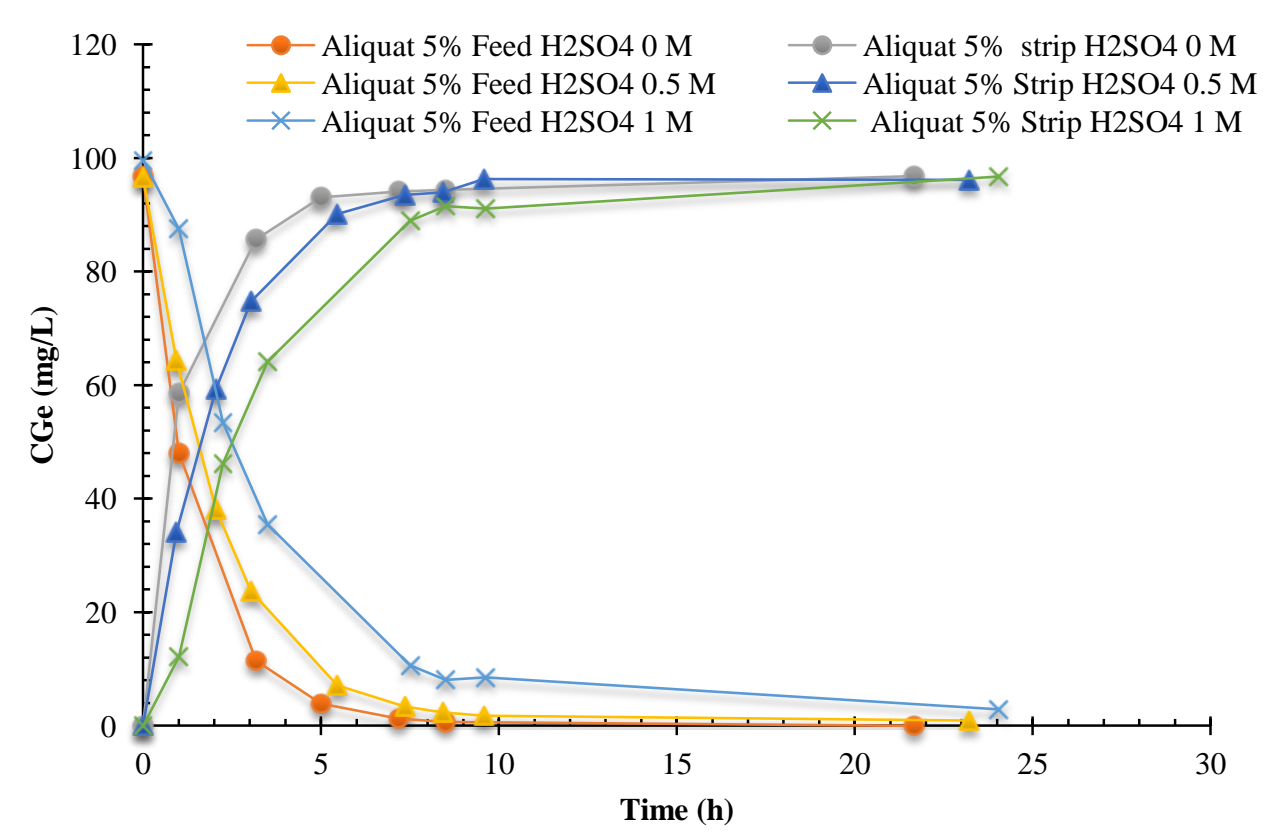


Fig. 9. The concentrations of germanium in the feed and strip phases vs. time in a sulfuric acid medium of 0,50 and $1 \mathrm{~mol} / \mathrm{L}$ as well as water medium $(\mathrm{Ge}, \mathrm{Ni}, \mathrm{Cd}$, and $\mathrm{Co}$ of $100 \mathrm{mg} / \mathrm{L}$ as well as $\mathrm{Zn} 15 \mathrm{~g} / \mathrm{L}$, Aliquat 336 concentration of $5 \% \mathrm{v} / \mathrm{v}$, the tartaric acid to Ge mole mass ratio of 2 and $\mathrm{HCl}$ strip solution concentration of $1 \mathrm{M}$ )

\subsection{Hollow fiber supported liquid membrane}

The hollow fiber supported liquid membrane is a developed supported liquid membrane with the same mechanism as FSSLM. However, HFSLM difference in comparison to FSSLM is in the structure of the membrane in which a cylindrical module with so much high interfacial area per unit is used.(Gabelman and Hwang, 1999) Because of this area, the transfer in HFSLM is faster than FSSLM. One of the aims for carrying out FSSLM experiments was to find an appropriate condition by which an experiment was conducted by the HFSLM technique. In this regard, a solution containing Ge, Ni, Cd, and Co of $100 \mathrm{mg} / \mathrm{L}$ along with $\mathrm{Zn}$ of $1000 \mathrm{mg} / \mathrm{L}$ was prepared in the presence of the optimum tartaric acid concentration mentioned in the FSSLM system. Aliquat $3365 \% \mathrm{v} / \mathrm{v}$ as a carrier and $\mathrm{HCl}$ solution with a concentration of $1 \mathrm{M}$ as a strip solution were used in the experiment. As mentioned in the experimental and method section, the feed volume was selected 4 times that of the strip phase volume to enrich germanium in this solution. This selection was a systematic choice and merely arbitrary for the test. Thus, it was expected that the concentration in the strip phase reached a maximum concentration of $400 \mathrm{mg} / \mathrm{L}$. The result of the experiment is illustrated in Fig. 10. As seen in this figure, the transport percentage of germanium in the feed phase was rapidly increased to reach a steady state. This state was achieved in less than $30 \mathrm{~min}$, which was comparable to liquid-liquid extraction equilibrium times. On the other hand, the germanium concentration enhanced in the strip phase with an expected factor of 4 times to reach a maximum concentration of $\approx 400 \mathrm{mg} / \mathrm{L}$. Due to the existence of mass transfer resistance restrictions corresponding to the strip side, the germanium 
enhancement rate in this side is lower than that of the feed side. Thus, as shown in Fig. 10, an amount of germanium remained in the membrane phase in the time range of $0-120 \mathrm{~min}$. Several researchers reported similar results.(Manna et al., 2014; Staszak et al., 2017; Wannachod et al., 2014) However, after an approximate time of $240 \mathrm{~min}$, all germanium ions were transported to the strip phase. This showed that the transport rate in HFSLM is much faster than that in the FSSLM system. Since no transports were observed for the other metals, their results are not presented here. Consequently, the HFSLM system of this study is an effective technique for the treatment of solutions such as leachates obtained from gasification fly ash leach liquors or wastewaters containing germanium.

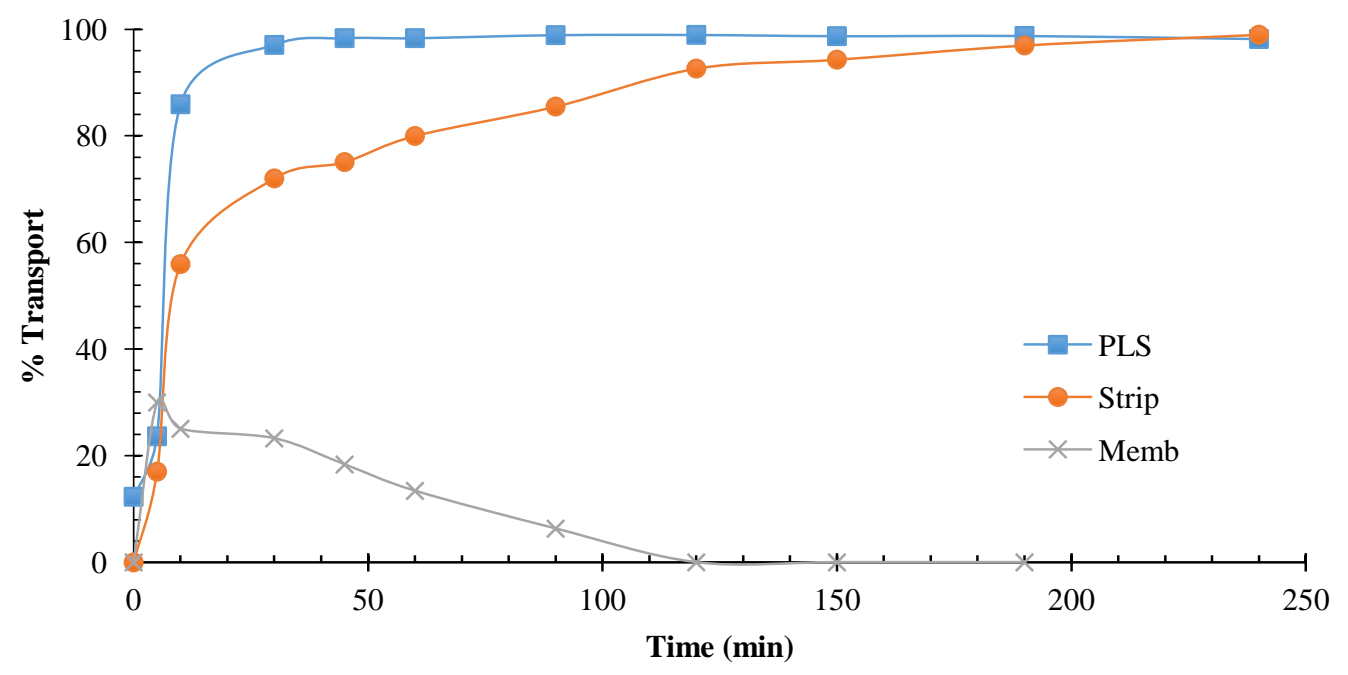

Fig. 10. Hollow fiber SLM results (Ge, Ni, Cd, and Co of $100 \mathrm{mg} / \mathrm{L}$ as well as $\mathrm{Zn} 1000 \mathrm{mg} / \mathrm{L}$, Aliquat 336 concentration of $5 \% \mathrm{v} / \mathrm{v}$, the tartaric acid to Ge mole mass ratio of 2 and $\mathrm{HCl}$ strip solution concentration of $1 \mathrm{M})$.

\section{Conclusion}

FSSLM processes using the carrier of Aliquat 336 were developed to transport germanium from the simulated gasification fly ash-water/zinc sulfuric acid leach liquors containing heavy metals. 
Adnan, S., Hoang, M., Wang, H., Xie, Z., 2012. Commercial PTFE membranes for membrane distillation application: Effect of microstructure and support material. Desalination 284, 297-308.

Arroyo, F., Fernández-Pereira, C., 2008. Hydrometallurgical recovery of germanium from coal gasification fly ash. Solvent extraction method. Industrial \& Engineering Chemistry Research 47, 31863191.

Arroyo, F., Fernández-Pereira, C., 2009. WO Patent: Method for the Recovery of Germanium in Solution by Means of Complexing and Use of Ion-Exchange Resins.

Arroyo, F., Fernández-Pereira, C., Olivares, J., Coca, P., 2009a. Hydrometallurgical recovery of germanium from coal gasification fly ash: pilot plant scale evaluation. Industrial \& Engineering Chemistry Research 48, 3573-3579.

Arroyo, F., Font, O., Fernández-Pereira, C., Querol, X., Juan, R., Ruiz, C., Coca, P., 2009b. Germanium recovery from gasification fly ash: Evaluation of end-products obtained by precipitation methods. Journal of Hazardous Materials 167, 582-588.

Bauer, é., D.R., C., G., F., P., Marchon, B., 1983. US patent: Process for Selective Liquid-Liquid Extraction of Germanium.

Bhatluri, K.K., Manna, M.S., Saha, P., Ghoshal, A.K., 2014. Supported liquid membrane-based simultaneous separation of cadmium and lead from wastewater. Journal of Membrane Science 459, 256-263.

Bhowal, A., Datta, S., 2001. Studies on transport mechanism of $\mathrm{Cr}(\mathrm{VI})$ extraction from an acidic solution using liquid surfactant membranes. Journal of Membrane Science 188, 1-8. 
Boateng, D.A.D., Neudorf, D.A., Saleh, V.N., 1990. Us patent: Recovery of Germanium From Aqueous Solutions by Solvent Extraction.

Campderrós, M.E., Marchese, J., 2001. Transport of niobium(V) through a TBP-Alamine 336 supported liquid membrane from chloride solutions. Hydrometallurgy 61, 89-95.

Chakrabarty, K., Krishna, K.V., Saha, P., Ghoshal, A.K., 2009. Extraction and recovery of lignosulfonate from its aqueous solution using bulk liquid membrane. Journal of Membrane Science 330, 135-144.

Chaturabul, S., Srirachat, W., Wannachod, T., Ramakul, P., Pancharoen, U., Kheawhom, S., 2015. Separation of mercury(II) from petroleum produced water via hollow fiber supported liquid membrane and mass transfer modeling. Chemical Engineering Journal 265, 34-46.

Chaudhary, S., Banerjee, D.K., 2007. Speciation of some heavy metals in coal fly ash. Chemical Speciation \& Bioavailability $19,95-102$.

Claassen, J.O., Meyer, E.H.O., Rennie, J., Sandenbergh, R.F., 2002. Iron precipitation from zinc-rich solutions: defining the Zincor Process. Hydrometallurgy 67, 87-108.

de Schepper, A., 1976. Liquid-liquid extraction of germanium by LIX 63. Hydrometallurgy 1, 291-298.

Duan, H., Wang, S., Yang, X., Yuan, X., Zhang, Q., Huang, Z., Guo, H., 2017. Simultaneous separation of copper from nickel in ammoniacal solutions using supported liquid membrane containing synergistic mixture of M5640 and TRPO. Chemical Engineering Research and Design 117, 460-471.

Everest, D.A., Harrison, J.C., 1960. 747. The chemistry of quadrivalent germanium. Part VIII. Complexes of germanium with tartaric, lactic, and mucic acid. Journal of the Chemical Society (Resumed), 37523758.

Fattahi, A., Rashchi, F., Abkhoshk, E., 2016. Reductive leaching of zinc, cobalt and manganese from zinc plant residue. Hydrometallurgy 161, 185-192.

Gabelman, A., Hwang, S.-T., 1999. Hollow fiber membrane contactors. Journal of Membrane Science 159, 61-106.

Harbuck, D.D., Judd, J.C., Behunin, D.V., 1991. GERMANIUM SOLVENT EXTRACTION FROM SULFURIC ACID SOLUTIONS (AND CO-EXTRACTION OF GERMANIUM AND GALLIUM). Solvent Extraction and Ion Exchange 9, 383-401.

Hiss, T.G., Cussler, E.L., 1973. Diffusion in high viscosity liquids. AIChE Journal 19, 698-703.

lorhemen, O.T., Hamza, R.A., Tay, J.H., 2016. Membrane Bioreactor (MBR) technology for wastewater treatment and reclamation: membrane fouling. Membranes 6, 33-62.

Ismael, M.R.C., Carvalho, J.M.R., 2003. Iron recovery from sulphate leach liquors in zinc hydrometallurgy. Minerals Engineering 16, 31-39.

Jha, M.K., Gupta, D., Lee, J.-c., Kumar, V., Jeong, J., 2014. Solvent extraction of platinum using amine based extractants in different solutions: A review. Hydrometallurgy 142, 60-69.

Kamran Haghighi, H., Irannajad, M., Fortuny, A., Sastre, A.M., 2018a. Recovery of germanium from leach solutions of fly ash using solvent extraction with various extractants. Hydrometallurgy 175, 164-169.

Kamran Haghighi, H., Irannajad, M., Moradkhani, D., 2018b. Facilitated transport of germanium from acidic medium through supported liquid membrane using Cyanex 301 as mobile carrier. Physicochemical Problems of Mineral Processing Article in Press.

Kamran Haghighi, H., Irannajad, M., Moradkhani, D., 2018c. Permeation and modeling studies on Ge(IV) facilitated transport using trioctylamine through supported liquid membrane. Korean J. Chem. Eng. 35, 53-60.

Kamran Haghighi, H., Moradkhani, D., Salarirad, M.M., 2015. Separation of zinc from manganese, magnesium, calcium and cadmium using batch countercurrent extraction simulation followed by scrubbing and stripping. Hydrometallurgy 154, 9-16.

Kamran Haghighi, H., Moradkhani, D., Sedaghat, B., Rajaie Najafabadi, M., Behnamfard, A., 2013. Production of copper cathode from oxidized copper ores by acidic leaching and two-step precipitation followed by electrowinning. Hydrometallurgy 133, 111-117. 
Kandwal, P., Dixit, S., Mukhopadhyay, S., Mohapatra, P.K., 2011. Mass transport modeling of Cs(I) through hollow fiber supported liquid membrane containing calix-[4]-bis(2,3-naptho)-crown-6 as the mobile carrier. Chemical Engineering Journal 174, 110-116.

Le, N.L., Nunes, S.P., 2016. Materials and membrane technologies for water and energy sustainability. Sustainable Materials and Technologies 7, 1-28.

Liang, D., Wang, J., Wang, Y., 2008. Germanium recovery by co-precipitation of germanium and iron in conventional zinc metallurgy. The Journal of The Southern African Institute of Mining and Metallurgy 108, 1-10.

Liu, D., Liu, H., Jiang, C., Leng, J., Zhang, Y., Zhao, Z., Zhuang, K., Jiang, Y., Ji, Y., 2015. Temperature dependence of the infrared optical constants of germanium films. Thin Solid Films 592, 292-295.

Liu, F., Liu, Z., Li, Y., Liu, Z., Li, Q., Zeng, L., 2016. Extraction of gallium and germanium from zinc refinery residues by pressure acid leaching. Hydrometallurgy 164, 313-320.

Manna, M.S., Saha, P., Ghoshal, A.K., 2014. Separation of medicinal catechins from tea leaves (Camellia sinensis) extract using hollow fiber supported liquid membrane (HF-SLM) module. Journal of Membrane Science 471, 219-226.

Marco-Lozar, J.P., Cazorla-Amorós, D., Linares-Solano, A., 2007. A new strategy for germanium adsorption on activated carbon by complex formation. Carbon 45, 2519-2528.

Nayl, A.A., 2010. Extraction and separation of $\mathrm{Co}(\mathrm{II})$ and $\mathrm{Ni}(\mathrm{II})$ from acidic sulfate solutions using Aliquat 336. Journal of Hazardous Materials 173, 223-230.

Nusen, S., Zhu, Z., Chairuangsri, T., Cheng, C.Y., 2015. Recovery of germanium from synthetic leach solution of zinc refinery residues by synergistic solvent extraction using LIX 63 and lonquest 801 . Hydrometallurgy 151, 122-132.

Panja, S., Ruhela, R., Misra, S., Sharma, J., Tripathi, S., Dakshinamoorthy, A., 2008. Facilitated transport of Am (III) through a flat-sheet supported liquid membrane (FSSLM) containing tetra (2-ethyl hexyl) diglycolamide (TEHDGA) as carrier. Journal of Membrane Science 325, 158-165.

Pokrovski, G.S., Schott, J., 1998. Experimental study of the complexation of silicon and germanium with aqueous organic species: implications for germanium and silicon transport and $\mathrm{Ge} / \mathrm{Si}$ ratio in natural waters. Geochimica et Cosmochimica Acta 62, 3413-3428.

Rathore, N.S., Leopold, A., Pabby, A.K., Fortuny, A., Coll, M.T., Sastre, A.M., 2009. Extraction and permeation studies of $\mathrm{Cd}(\mathrm{II})$ in acidic and neutral chloride media using Cyanex 923 on supported liquid membrane. Hydrometallurgy 96, 81-87.

Rieke, G.H., 2007. Infrared detector arrays for astronomy. Annu. Rev. Astron. Astrophys. 45, 77-115.

Sadeghi, N., Moghaddam, J., Ilkhchi, M.O., 2017. DETERMINATION OF EFFECTIVE PARAMETERS IN PILOT PLANT SCALE DIRECT LEACHING OF A ZINC SULFIDE CONCENTRATE. Physicochem. Probl. Miner. Process 53, 601-616.

Sethurajan, M., Huguenot, D., Jain, R., Lens, P.N.L., Horn, H.A., Figueiredo, L.H.A., van Hullebusch, E.D., 2017. Leaching and selective zinc recovery from acidic leachates of zinc metallurgical leach residues. Journal of Hazardous Materials 324, Part A, 71-82.

Sijakova-Ivanova, T., Panov, Z., Blažev, K., Zajkova-Paneva, V., 2011. Investigation of fly ash heavy metals content and physico chemical properties from thermal power plant, Republic of Macedonia. International Journal of Engineering Science and Technology (IJEST) 3, 8219-8225.

Staszak, K., Wojciechowska, A., Reis, M.T.A., Wojciechowska, I., Wieszczycka, K., Ismael, M.R.C., Carvalho, J.M.R., 2017. Recovery of zinc(II) from chloride solutions using pseudo-emulsion based hollow fiber strip dispersion with pyridineketoxime extractants. Separation and Purification Technology 177, 152-160.

Strzelbicki, J., Charewicz, W.A., Mackiewicz, A., 1984. Permeation of chromium (VI) and rhenium (VII) oxyanions through liquid organic membranes facilitated by quaternary ammonium chlorides. Separation Science and Technology 19, 321-336. 

solvent extraction using Cyanex 272 as an extractant: A comparison study. Journal of Membrane Science 288, 139-148.

Swain, B., Mishra, C., Jeong, J., Lee, J.-C., Hong, H.S., Pandey, B.D., 2015. Separation of Co(II) and Li(I) with Cyanex 272 using hollow fiber supported liquid membrane: A comparison with flat sheet supported liquid membrane and dispersive solvent extraction process. Chem. Eng. J. 271, 61-70.

Swain, B., Sarangi, K., Das, R.P., 2006. Effect of different anions on separation of cadmium and zinc by supported liquid membrane using TOPS-99 as mobile carrier. Journal of Membrane Science 277, 240248.

Takemura, H., Morisada, S., Ohto, K., Kawakita, H., Matsuo, Y., Fukuda, D., 2013. Germanium recovery by catechol complexation and subsequent flow through membrane and bead-packed bed column. J. Chem. Technol. Biotechnol. 88, 1468-1472.

Vartapetian, O., 1957. Contribution a l'etude des complexes du germanium et de quelques acides aalcools. Ann. Chem. 2, 917-965.

Venkateswaran, P., Palanivelu, K., 2005. Studies on recovery of hexavalent chromium from plating wastewater by supported liquid membrane using tri-n-butyl phosphate as carrier. Hydrometallurgy 78 , 107-115.

Vibhute, C.P., Khopkar, S.M., 1986. Solvent extraction separation of germanium with Aliquat $336 \mathrm{~S}$ from citric acid solutions. Bulletin of the Chemical Society of Japan 59, 3229-3232.

Wannachod, T., Leepipatpiboon, N., Pancharoen, U., Nootong, K., 2014. Separation and mass transport of $\mathrm{Nd}(\mathrm{III})$ from mixed rare earths via hollow fiber supported liquid membrane: Experiment and modeling. Chemical Engineering Journal 248, 158-167.

Wei, W., Cho, C.-W., Kim, S., Song, M.-H., Bediako, J.K., Yun, Y.-S., 2016. Selective recovery of Au (III), Pt (IV), and Pd (II) from aqueous solutions by liquid-liquid extraction using ionic liquid Aliquat-336. Journal of Molecular Liquids 216, 18-24.

Won, S.W., Kotte, P., Wei, W., Lim, A., Yun, Y.-S., 2014. Biosorbents for recovery of precious metals. Bioresource Technology 160, 203-212.

Yang, X.J., Fane, A.G., Pin, C., 2002. Separation of zirconium and hafnium using hollow fibers. Chemical Engineering Journal 88, 37-44.

Zhang, J., Duke, M., Ostarcevic, E., Dow, N., Gray, S., Li, J.-d., 2009. Performance of new generation membrane distillation membranes. Water Science and Technology: Water Supply 9, 501. 